\title{
Metrological SeT-UP For CALibrating 1D LiNE SCAleS With Sub-Micrometre Precision
}

\author{
Rok Klobucar, Branko Strbac, Miodrag Hadzistevic, Bojan Acko
}
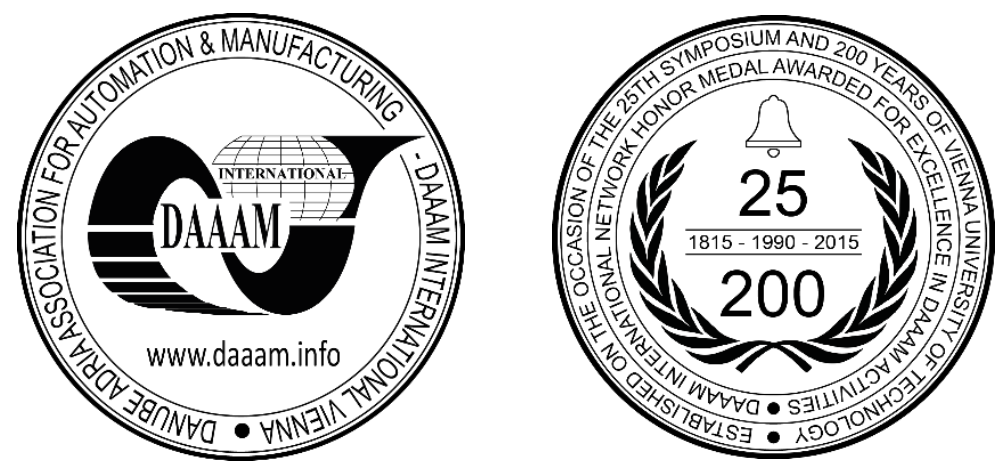

This Publication has to be referred as: Klobucar, R[ok]; Strbac, B[ranko] M[ile]; Hadzistevic, M[iodrag] \& Acko, B[ojan] (2017). Metrological set-up for Calibrating 1D Line Scales with Sub-Micrometre Precision, Proceedings of the 28th DAAAM International Symposium, pp.0537-0544, B. Katalinic (Ed.), Published by DAAAM International, ISBN 978-3-902734-11-2, ISSN 1726-9679, Vienna, Austria

DOI: $10.2507 / 28$ th.daaam.proceedings.076

\begin{abstract}
The use of the optical standards in the industry is constantly growing. A high resolution 1D measurement instrument developed for calibrating precision line scales with sub-micrometre measurement uncertainty is presented in this paper. The mechanical foundation of this instrument is based around a custom designed, numerically controlled multi-axis granite stage manufactured by Newport Micro-Controle Spectra-Physics, but specifically designed to meet the metrological requirements of the Laboratory for Production Measurement (LTM) at the University of Maribor. The system integrates a numerically controlled multi-axis stage, a laser interferometer, and a vision system for detecting line position. The measurement and the analysis processes are completely automated in order to minimize manual labour during the calibration process, but also increase the calibration accuracy. Increasing calibration accuracy leads up to better quality of industrial measurements which is required by modern precision industry. The metrological capabilities of the presented measurement set-up were verified by some practical test measurements. Indirect users of the results of this research will be all manufacturers of precise products such as automotive and other industries.
\end{abstract}

Keywords: Measurement; high resolution measurements; multi-axis stage; metrological set-up; line scales; measurement uncertainty

\section{Introduction}

Industry is demanding more and more rapid and accurate dimensional measurements on diverse mechanical parts. In recent years, optical coordinate measuring machines (CMMs) having made substantial progress and are now often used for such applications. Especially CMMs equipped with imaging capabilities are frequently used for fast, non-contact measurements. Strong competition among manufacturers of such instruments and the demand for sub-micron accuracy has led to standardised tests, which are aimed for comparing and validating instrument performance [1]. Calibration, verification and also error correction of optical CMMs are mainly based on measurements using reference line scales or two-dimensional grid plates [2, 3, 4].

There are very many commercially available line scales made of different materials (steel, brass, invar, glass, quartz, zerodur). They can vary in length from below $1 \mathrm{~mm}$ to more than $1 \mathrm{~m}$, and have resolutions (pitch) from below $10 \mathrm{~nm}$ to $1 \mathrm{~cm}$. They can be calibrated by using different measurement set-ups, depending on their length and precision. Set-ups 
for calibrating high-precision line scales normally involve a microscope with an optical sensor for capturing and analysing the image of a line marker and a laser interferometer as a traceable measurement standard [5-7].

This paper introduces a measuring system developed for calibrating line scales with measurement uncertainty of less than $10 \mathrm{~nm}$ over a total length of $500 \mathrm{~mm}$. The system integrates a numerically controlled multi-axis stage, a laser interferometer, and a vision system for detecting line position. With this measurement set-up, Abbe errors can be reduced to negligible levels. Spatial separation between the measured point and reference line is known as an Abbe offset [8].

Since it is possible to put optical components very close to each other, the air dead path error of the laser interferometer is also negligible. Software for detecting of the lines is based on earlier design from 2009 [9, 10]. In order to improve performance and to achieve better uncertainty, the software was improved and automatized, mechanics and optics have been redesigned and several uncertainty components better characterized. This facility will replace the old measurement facility that is manually operated. A model for evaluating uncertainty and the uncertainty budget for the demonstrated measuring system is presented in the paper.

\section{Measurement system}

Measurement set-up for calibrating line scales is shown in Fig. 1., while its schematic diagram is shown in Fig. 2. The system integrates a numerically controlled multi-axis stage, a laser interferometer, and a vision system for detecting line position [11].

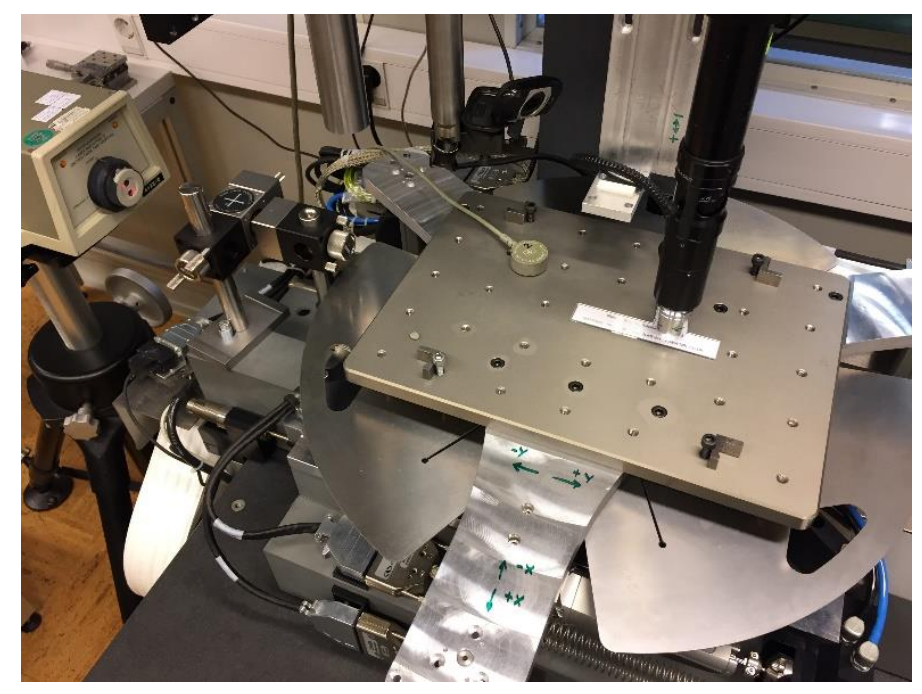

Fig. 1. Measurement set-up for calibrating line scales

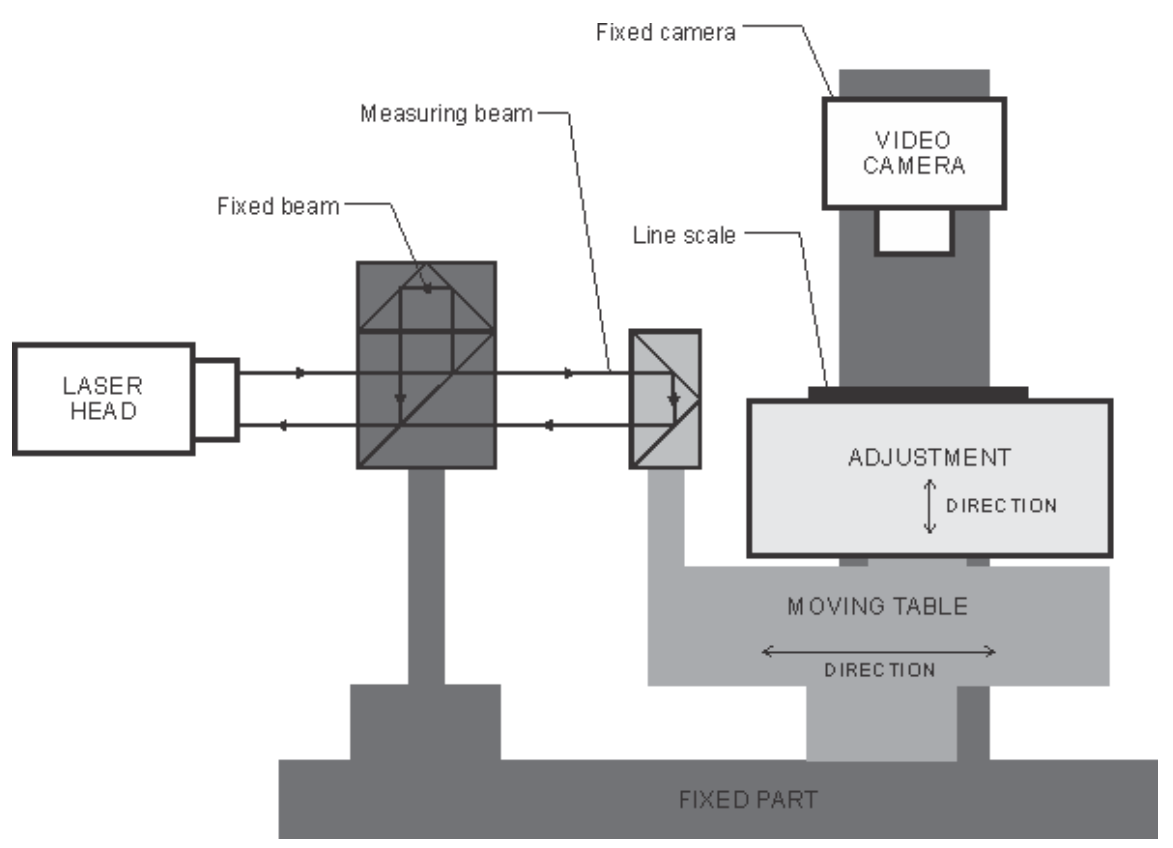

Fig. 2. Schematic diagram of measurement set-up for calibrating line scales 


\subsection{Numerically controlled multi-axis stage}

Numerically controlled multi-axis stage is shown in Fig. 3. It was designed and manufactured by Newport-micro controle [12] for the Laboratory for Production Measurement (LTM), University of Maribor, Slovenia. The measuring system designed by the LTM is intended to perform 2D measurements on various objects, which will be fixed on a measuring table. This research is focused in 1D measurements. Newport's solution is based on a HybrYX-G5 stage featuring a ceramic carriage which freely slides in $\mathrm{X}$ and $\mathrm{Y}$ axes on a precision lapped granite reference plate, using proprietary pressure-vacuum air bearing design. The carriage is guided along $\mathrm{Y}$ axis by a rigid ceramic beam. The beam is supported and guided at each end with the ball bearing carriages of $\mathrm{X}$ axis. Both $\mathrm{X}$ and $\mathrm{Y}$ axes are motorized with linear actuators and include linear glass encoders. Both linear scale glass encoders are LIDA403 made by Heidenhain, length $440 \mathrm{~mm}$ for $\mathrm{X}$ axis and length $1250 \mathrm{~mm}$ for $\mathrm{Y}$ axis. This positioning system is equipped with the optional Z-Tip-Tilt and Theta stage. It is motorized by precision actuators equipped with miniature DC servo motors. The position system is built on a heavy granite table, which features a precision reference plane for the air bearing carriage. In addition, the granite structure includes a granite gantry allowing the fixation of a vertical motorized translation stage, which accommodates the measuring sensor, depending on an application. Two rails mounted on the gantry equipped with sliding carriages provide manual rough positioning capability. The granite structure is set on a heavy welded frame equipped with ND40 passive isolators. The position system has one XPS motion controller including dedicated drivers for the five DC motors and the three linear motors.

The $\mathrm{X}$ axis is dual axis composed of $\mathrm{X} 1$ and $\mathrm{X} 2$ actuators mounted on the flanks at both ends of the granite table. X1 and X2 carriages move the ceramic beam of the $Y$ axes. The $X$ axis travel range is $+/-175 \mathrm{~mm}$. It has a linear encoder with $5 \mathrm{~nm}$ resolution. The maximal speed is $300 \mathrm{~mm} / \mathrm{s}$., while the repeatability is $500 \mathrm{~nm}$.

The $\mathrm{Y}$ axis is a horizontal translation stage using air bearing technology and linear motor. The guiding beam of $\mathrm{Y}$ axes sub-assembly is attached to the carriages of the X1 and X2 short travel translation actuators. The guideways involve two parts: a large ceramic carriage and a Y-axis guide ceramic L-shape beam. The ceramic carriage freely slides in X and $\mathrm{Y}$ axes using pressure-vacuum air bearing design. The reference planes for the air bearing carriage are the precision lapped surface of the granite table and the vertical slide of the $\mathrm{Y}$ rigid ceramic beam. The $\mathrm{Y}$ axis travel range is $+/-500 \mathrm{~mm}$. It contains a linear encoder with $5 \mathrm{~nm}$ resolution. Maximum speed is $600 \mathrm{~mm} / \mathrm{s}$., while the repeatability is $100 \mathrm{~nm}$.

The ZTT Theta stage is mounted on the air bearing carriage; it is equipped at the top with the measuring platform, which allows installing measured objects. All axes are driven by the high precision motorized linear actuators. Three actuators are set in upright position with a travel range of $10 \mathrm{~mm}$. One actuator is set horizontally to achieve the theta $\mathrm{Z}$ movement with a travel range of $+/-1^{\circ}$. All four actuators are equipped with a miniature DC motor made by Fulhaber.

$\mathrm{Z}$ axis is a vertical motorized translation stage on the middle carrier. It is a Newport catalogue stage reference MIMS100V. The $\mathrm{Z}$ axis travel range is $100 \mathrm{~mm}$, the minimum incremental motion is $0,3 \mu \mathrm{m}$, the encoder resolution is 0,1 $\mu \mathrm{m}$, the maximum speed is $20 \mathrm{~mm} / \mathrm{s}$, while the repeatability is $\pm 0,5 \mu \mathrm{m}$.

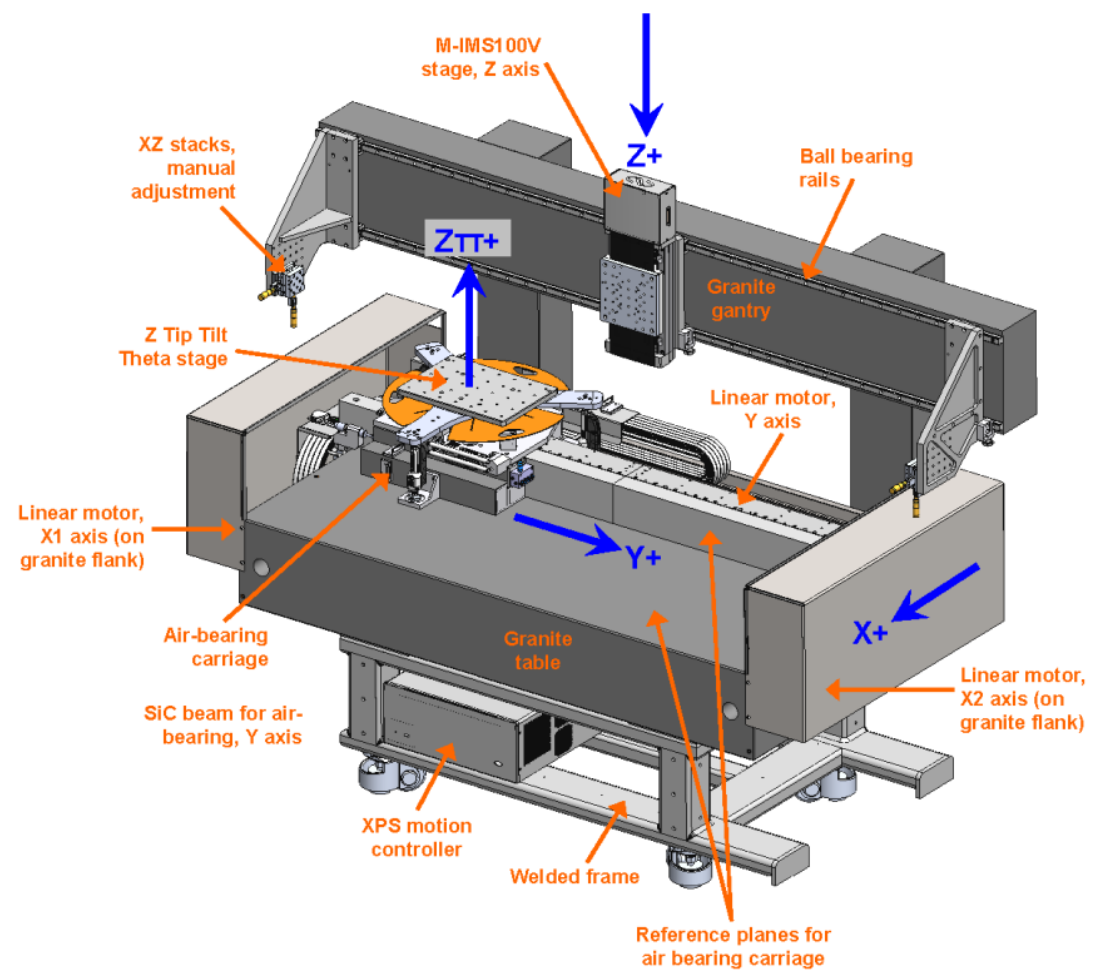

Fig. 3. Numerically controlled multi-axis stage 


\subsection{Laser interferometer}

Laser interferometer position measurement systems provide very precise position or distance information [15]. Our system consists of a laser head HP 5528A, Agilent module 55292A, and a variety of optical components and accessories such as material sensors and air sensor. The basic system measures linear displacement. The system uses the wavelength of light from a low-power helium-neon laser as a length standard. We normally set the resolution of the laser interferometer to $10 \mathrm{~nm}$.

Special mounting elements were constructed for the optics used for calibration. A schematic diagram of the laser interferometer and the position of the optics are shown in Fig. 2. The position of the optical elements and the moving parts are set in such way, that the measured object axis is set in the line with the centre of the laser linear retroreflector. It allows the Abbe errors to be reduced to negligible levels even for the most demanding dimensional metrology tasks [13]. The linear interferometer is fixed on the fixed part of the stage, while the retroreflector is placed on the moving table in the horizontal direction. Only the measured object is placed on the moving table that can move in the vertical direction.

\subsection{Vision system for detecting line position}

The vision system for detecting line position consists of a zoom microscope and a CMOS digital camera. The camera is connected to the computer via USB 3.0 port. The CMOS camera gets the images of the line scale and sends them to the computer software.

The software analyses the images and determinates the middle of the line., which is defended by the operator. The software calculates the distance in pixels. The CMOS digital camera takes 15 monochrome images per second in resolution 2592 x 1944 pixels. The software analyses the images in real time. The distance calculated in pixels is transformed into micrometers [14]. The software for calculation the distance between lines is more detailed presented by the authors in paper [10].

\section{Uncertainty of measurement}

Line scales are material measures made of glass, steel or other material, on which dimensions are marked with line marks. Since the materials have quite different temperature expansion coefficients, which are in many cases not exactly known, they are stabilized before calibration in the climatic room at $20{ }^{\circ} \mathrm{C}$ for 24 hours. The measurement system must be adjusted and initialized before the measurement. The line scale should be positioned under the camera by moving the measurement table. The measuring system, laser interferometer, vision system for detecting line position and line scale should be adjusted according to the measuring direction, which is defended by the movement of the horizontal direction of the table. The line scale should be fixed on the adjustment table under the camera.

The camera is fixed. It is adjusted in such a way, that the focus of the camera intersects the centre of the laser linear retroreflector. The camera is focused on the lines of the line scale by moving the adjustment table (ZTT Theta stage) in the vertical direction. With this procedure, the line scale axis, the images of the lines and the centre of the laser linear retroreflector with the laser beam are positioned in the measuring direction.

The image processing software should be initialized [10]. With the improved software, connection to the numerically controlled multi-axis stage and connection to the laser head, automatic measurements of distances are possible. The measurement goal is to measure distances between the reference line and the chosen measuring lines on the line scale automatically. Measured data are saved into the file where they are ready for further processing.

\subsection{Mathematical model of measurement}

The measured value in the calibration of a line scale is a deviation from a nominal distance between two line centres. The distance between two lines is calculated as a sum of laser interferometer indication and vision system for detecting line position indication. The vision system for detecting line position measures the distance between the measurement point (scale mark) and the reference line. Deviation $e$ (measurement result) is given by the expression:

$$
e=\left(L_{\mathrm{LI}}+L_{\mathrm{V}}-L_{\mathrm{LIref}}\right) \cdot\left(1+\alpha_{\mathrm{m}} \cdot \theta_{\mathrm{m}}\right)-N+e_{\mathrm{cos}}+e_{\mathrm{mp}}+e_{\mathrm{ms}}+e_{\mathrm{a}}
$$

where:

$e \quad$ deviation (measurement result) at $20^{\circ} \mathrm{C}$

$L_{\mathrm{LI}} \quad$ corrected length shown by laser interferometer

$L_{\mathrm{V}} \quad$ distance between the measurement point (scale mark) and reference line in the image window

$L_{\text {LIref }}$ indication on the laser in the reference (origin) point

$\alpha_{\mathrm{m}} \quad$ linear temperature expansion coefficient of the scale 
$\theta_{\mathrm{m}} \quad$ temperature deviation of the scale from $20^{\circ} \mathrm{C}$

$N$ nominal value (without uncertainty)

$e_{\text {cos }} \quad$ cosine error of measurement (supposed to be 0 )

$e_{\mathrm{mp}}$ dead path error

$e_{\mathrm{ms}} \quad$ random error caused by uncontrolled mechanical changes

$e_{\mathrm{a}} \quad$ error caused by the measuring table inclination

\subsection{Standard and expanded uncertainty}

For uncorrelated input quantities the square of the standard uncertainty associated with the output estimate $y$ is given by (2) [14]:

$$
u^{2}(y)=\sum_{\mathrm{i}=1}^{\mathrm{N}} u_{\mathrm{i}}^{2}(y)
$$

The quantity $u_{\mathrm{i}}(y)(i=1,2, \ldots, N)$ is the contribution to the standard uncertainty associated with the output estimate $\mathrm{y}$ resulting from the standard uncertainty associated with input estimate $x_{\mathrm{i}}$ [14]:

$$
u_{i}(y)=c_{i} \cdot u\left(x_{i}\right)
$$

where $c_{i}$ is the sensitivity coefficient associated with the input estimate $x_{i}$, i.e. the partial derivative of the model function $f$ with respect to $X_{i}$, evaluated at the input estimates $x_{i}$ [14].

$$
c_{i}=\frac{\partial f}{\partial x_{i}}=\left.\frac{\partial f}{\partial X_{i}}\right|_{X_{1}=x_{1} \ldots X_{N}=x_{N}}
$$

\begin{tabular}{|c|c|c|c|c|c|}
\hline $\begin{array}{c}\text { Value } \\
\boldsymbol{X}_{\boldsymbol{i}}\end{array}$ & $\begin{array}{c}\text { Estimated } \\
\text { value }\end{array}$ & $\begin{array}{c}\text { Standard } \\
\text { Uncertainty }\end{array}$ & Distribution & $\begin{array}{c}\text { Sensitivity } \\
\text { coefficient }\end{array}$ & $\begin{array}{c}\text { Uncertainty } \\
\text { contribution }\end{array}$ \\
\hline$L_{\mathrm{LI}}$ & $0 \mathrm{~mm}$ & $13 \mathrm{~nm}+0,2 \cdot 10^{-6} \cdot L$ & normal & 1 & $13 \mathrm{~nm}+2,5 \cdot 10^{-7} \cdot L$ \\
\hline$L_{\mathrm{V}}$ & $<5 \mu \mathrm{m}$ & $25 \mathrm{~nm}$ & normal & 1 & $25 \mathrm{~nm}$ \\
\hline$L_{\mathrm{LIref}}$ & $0 \mathrm{~mm}$ & $9 \mathrm{~nm}$ & normal & -1 & $9 \mathrm{~nm}$ \\
\hline$\alpha_{\mathrm{m}}$ & $10^{-5}{ }^{\circ} \mathrm{C}^{-1}$ & $1,15 \cdot 10^{-6}{ }^{\circ} \mathrm{C}^{-1}$ & rectangular & $0,05^{\circ} \mathrm{C} \cdot L$ & $0,06 \cdot 10^{-6} \cdot L$ \\
\hline$\theta_{\mathrm{m}}$ & $0{ }^{\circ} \mathrm{C}$ & $0,05{ }^{\circ} \mathrm{C}$ & normal & $10^{-5}{ }^{\circ} \mathrm{C}^{-1} \cdot L$ & $0,05 \cdot 10^{-5} \cdot L$ \\
\hline$e_{\mathrm{cos}}$ & 0 & $0 \mathrm{~nm}$ & normal & 1 & $0 \mathrm{~nm}$ \\
\hline$e_{\mathrm{mp}}$ & 0 & $9 \mathrm{~nm}$ & rectangular & 1 & $9 \mathrm{~nm}$ \\
\hline$e_{\mathrm{ms}}$ & 0 & $30 \mathrm{~nm}$ & normal & 1 & $30 \mathrm{~nm}$ \\
\hline$e_{\mathrm{a}}$ & 0 & $13 \mathrm{~nm}$ & rectangular & 1 & $13 \mathrm{~nm}$ \\
\hline
\end{tabular}

Table 1. Uncertainty budget for calibration of line scales

The expanded uncertainty for the coverage factor $\mathrm{k}=2$ is then:

$$
U=\sqrt{(90 \mathrm{~nm})^{2}+\left(1,1 \cdot 10^{-6} \cdot L\right)^{2}}
$$

\section{Experimental results}

The measurement accuracy of the numerically controlled multi-axis stage was verified with the laser interferometer [10] in Y direction over the distance ( 0 to 500$) \mathrm{mm}$ by twenty repeated measurements in eleven positions. The absolute difference between the reference value shown by the laser interferometer and the encoder value in the $\mathrm{Y}$ axis of the measuring system is shown in Fig. 4. 


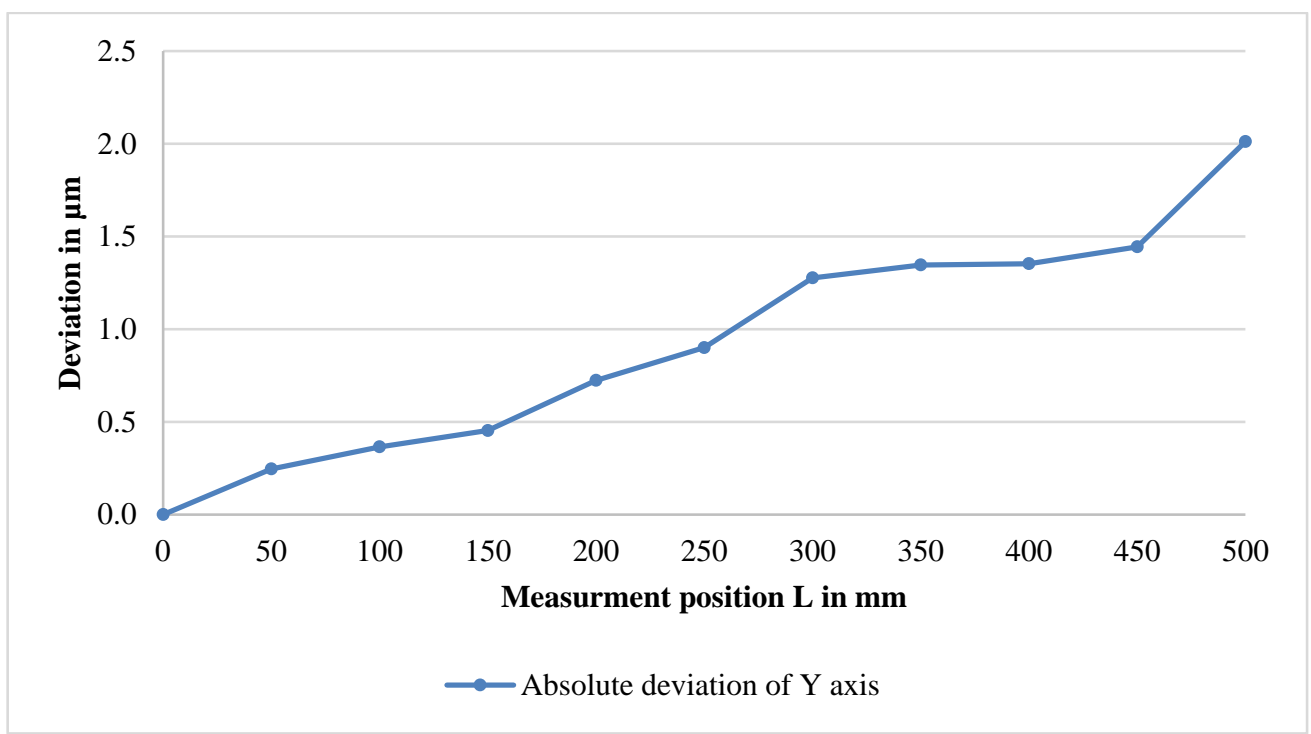

Fig. 4. Absolute deviation between laser values and encoder value

Experimental standard deviation that reflects random influences is shown in the diagram in Fig. 5. Random influences are caused by the multi-axis stage instability, vibrations and random changes of environmental conditions. Presented standard deviations were used in uncertainty budged of the calibration procedure.

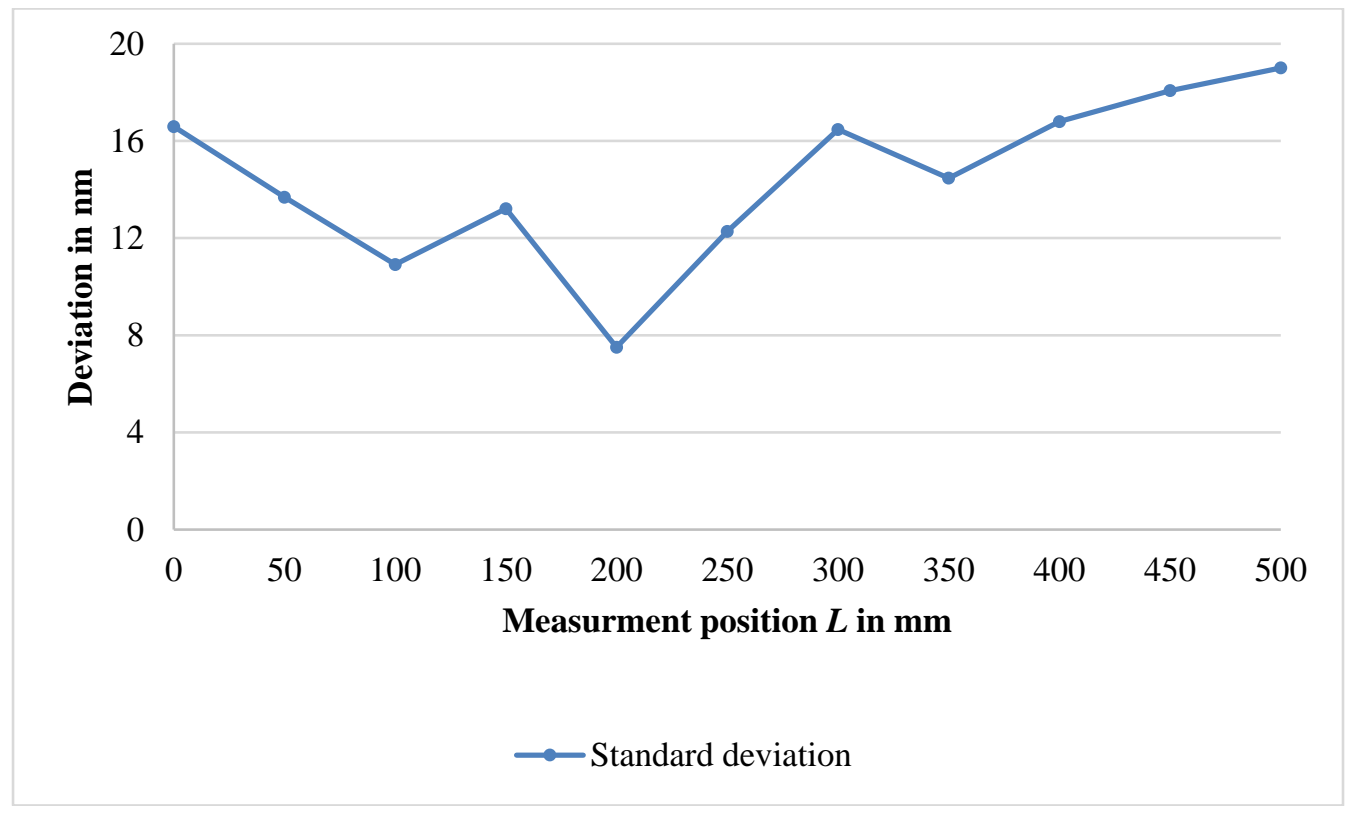

Fig. 5. Standard deviation on measurement positions

Measurement accuracy of the measuring system was verified on a calibrated line scale over the distance (0 to 100) $\mathrm{mm}$. Experimental standard deviation $\mathrm{s}(L)(6)$ :

$$
s(L)=\sqrt{\frac{1}{n-1} \sum_{j=1}^{n}\left(L_{j}-\bar{L}\right)^{2}}
$$

that reflects random influences is shown in the diagram in Fig. 6. The diagram also represents the deviation of measured values from the reference and estimated standard uncertainty. These results characterize the measuring system which will allow calibrations of length measurements without laser interferometer. Measuring results represent a linear characteristic. It is possible to compensate the error with the appropriate error mapping. From the results, we can see that it is possible to improve the measurement uncertainty. 


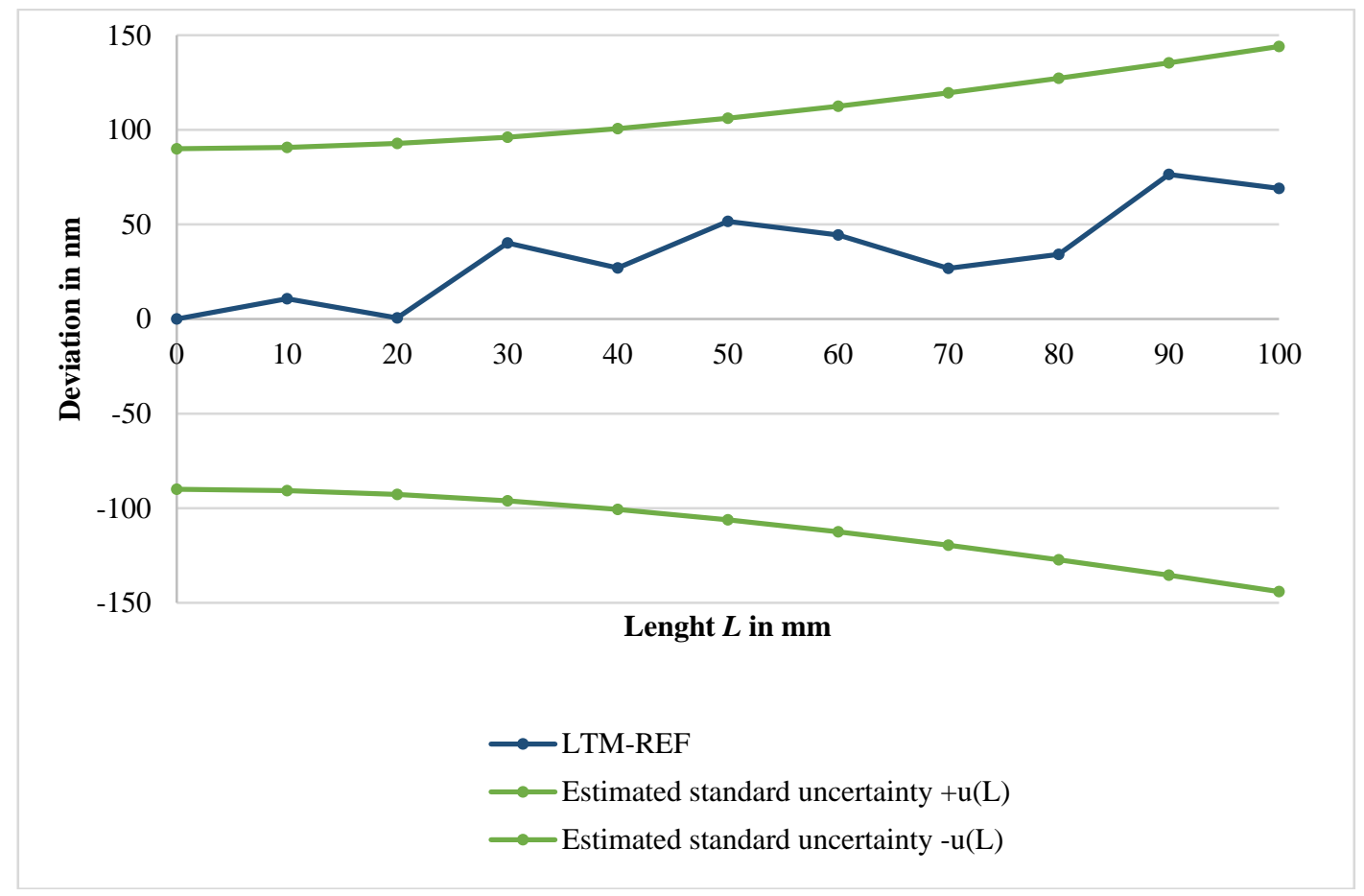

Fig. 6. Deviation of measured values from reference and estimated standard uncertainty

\section{Conclusion}

The main result of the presented research is a verified measuring set-up for calibrating precise line scales. The system integrates a numerically controlled multi-axis stage, a laser interferometer, and a vision system for detecting line position.

The presented procedure for calibrating line-scales with lengths up to $500 \mathrm{~mm}$, with the measuring uncertainty expressed by (5) has already been accredited by the national accreditation body. In respect to the previous measurement set-up, we have improved the measuring system with new automatic numerical controlled multi-axis stage, better camera and better environmental conditions. Better calibration and measurement capability (CMC) was achieved and approved. The calibration, verification and also error correction of optical CMMs is mainly based on measurements using reference line scales or two-dimensional grid plates. Our further work will focus on calibrating 2D optical grids and step gauges. One of the final goals of this validation phase was to determine uncertainty of measurement in calibration and verification of new automatic high resolution measuring set-up for calibrating precise line scales.

\section{Acknowledgment}

The authors acknowledge the financial support from the Slovenian Research Agency (research core funding No. P20190), as well as from Metrology Institute of the Republic of Slovenia (funding of national standard of length; contract No. C3212-10-000072). The research was performed by using equipment financed from the European Structural and Investment funds (Measuring instrument for length measurement in two coordinates with sub-micrometer resolution; contract with MIRS No. C2132-13-000033).

\section{References}

[1] Meli, F. (2013). Calibration of photomasks for optical coordinate metrology, Physikalisch-Technische Bundesanstalt (PTB), doi: 10.7795/810.20130620C

[2] Mariko, K.; Tsukasa, W.; Makoto, A., \& Toshiyuki, T. (2015). Calibrator for 2D Grid Plate Using Imaging Coordinate Measuring Machine with Laser Interferometers, International Journal of Automation Technology, Vol. 9, No. 5, pp. 541-545, doi: 10.20965/ijat.2015.p0541

[3] Ačko, B.; Brezovnik, S.; Črepinšek-Lipuš, L. \& Klobučar, R. (2015). Verification of statistical calculations in interlaboratory comparisons by simulating input datasets, International journal of simulation modelling, Vol. 14, No. 2, pp. 227-237, doi: 10.2507/IJSIMM14(2)4.288

[4] Ačko, B.; Sluban, B.; Tasič, T. \& Brezovnik, S. (2014). Performance metrics for testing statistical calculations in interlaboratory comparisons, Advances in Production Engineering \& Management, Vol. 9, No. 1, pp. 44-52, doi: 10.14743/apem2014.1.175 
[5] Flügge, J.; Köning, R.; Weichert, Ch.; Häßler-Grohne, W.; Geckeler, R. D.; Wiegmann, A.; Schulz, M.; Elster, C. \& Bosse, H. (2009). Development of a 1.5D reference comparator for position and straightness metrology on photomasks, Proc. SPIE 7122, Photomask Technology 2008, doi:10.1117/12.801251

[6] Ačko, B. (2012). Final report on EUROMET Key Comparison EUROMET.L-K7: Calibration of line scales, Metrologia, Vol. 49, doi: 10.1088/0026-1394/49/1A/04006

[7] Lassila, A. (2012). MIKES fibre-coupled differential dynamic line scale interferometer, Measurement Science and Technology, Vol. 23, No. 9, doi: 10.1088/0957-0233/23/9/094011

[8] Leach, R. (2015). Abbe Error/Offset, CIRP Encyclopaedia of Production Engineering, Springer, Berlin, DE, 1-4, doi: 10.1007/978-3-642-35950-7_16793-1

[9] Klobučar, R. \& Ačko, B. (2016). Experimental evaluation of ball bar standard thermal properties by simulating real shop floor conditions, International journal of simulation modelling, Vol. 15, No. 3, pp. 511-521, doi:10.2507/ijsimm15(3)10.356

[10] Družovec, M.; Ačko, B.; Godina, A. \& Welzer, T. (2009). Robust algorithm for determining line centre in video position measuring system, Optics and Lasers in Engineering, Vol.47, pp. 1131-1138, doi: 10.1016/j.optlaseng.2009.06.017

[11] Klobucar, R. \& Acko, B. (2017). Automatic high resolution measurement set-up for calibrating precise line scales, Advances in Production Engineering \& Management, Vol. 12, No. 1, pp. 88-96, doi: 10.14743/apem2017.1.242

[12] Newport Corporation. Air Bearing Solution Guide, from https://www.newport.com/g/air-bearing-solutionselection-guide, Accessed on: 2017-06-15

[13] Köning , R.; Weichert, C.; Köchert, P.; Guan, J. \& Flügge, J. (2013). Redetermination of the Abbe Errors' Uncertainty Contributions at the Nanometer Comparator, In: Proceedings of the 9th International Conference, Smolenice, Slovakia, pp. 171-174

[14] EA-4/02. Evaluation of the uncertainty of measurement in calibration, from http://www.europeanaccreditation.org/publication/ea-4-02-m-rev01-september-2013, Accessed on: 2017-06-18

[15] Lipus, L.C.; Budzyn, G.; Rzepka, J. \& Acko, B. (2016). Calibration capability with laser frequency standard, DAAAM International Scientific Book 2016, pp. 197-206, doi: 10.2507/daaam.scibook.2016.18 